\title{
The Influence of Knowledge-Based HRM Practices on Productivity of Knowledge Workers: A Study on Malaysian Universities
}

\author{
Leong Kai Sheng \\ Sunway University Business School \\ Sunway University, \\ Malaysia \\ leongkaisheng96@gmail.com
}

\author{
Dr Shehnaz Tehseen \\ Lecturer, Department of Management, Sunway University \\ Business School, Sunway University, No.5 Jalan Universiti \\ Bandar Sunway, Malaysia \\ shehnazt@sunway.edu.my
}

\author{
Dr. Sheikh Muhamad Hizam Sheikh Khairuddin \\ Senior Lecturer, University Kuala Lumpur Business School, \\ Level 8, Bangunan Yayasan Selangor, No.74, Jalan Raja \\ Muda Abdul Aziz, 50300 Kuala Lumpur, Malaysia \\ sheikhmhizam@unikl.edu.my
}

Yeong Hui Yan

Lecture, Department of Management, Sunway University Business School, Sunway University, No. 5 Jalan Universiti, Bandar Sunway, Malaysia huiyany@sunway.edu.my

\begin{abstract}
Knowledge workers have contributed significantly to the development of nations. There are various researches that extensively recognized the positive impact of knowledge-based HRM practices on knowledge worker's productivity. While there are studies regarding knowledge-based HRM practices across different countries and industries, however, there is dearth of research regarding the impact of knowledge-based HRM practices on universities' knowledge workers. Therefore, the aim of this current study was to fill up the gap by analysing the influence of various knowledge-based HRM practices on the productivity of knowledge workers in universities. This study investigated HRM practices namely knowledge-based recruiting practices, knowledge-based training and development practices, knowledge-based performance appraisal practices and knowledge-based compensation practices on the quality and quantity of the productivity of knowledge workers. Herzberg's Two-Factor Theory, Expectancy Theory, and MacGregor's Theory $X$ and Theory $Y$ were used as underpinning theories to support the proposed conceptual model. Eight hypotheses were developed based on the proposed research model and standard instrument was used to obtain data. By employing nonprobability sampling method, a total of 129 knowledge workers in Selangor and Kuala Lumpur participated in survey. The data were collected at one point of time across the sample population. The data obtained were assessed using SPSS and Partial Least Square Structural Equation Modelling (PLS-SEM). Results revealed the positive and significant influence of knowledgebased recruiting practices and knowledge-based compensation practices on quality and quantity of knowledge workers' productivity. Knowledge-based training and development practices were found to have their positive and significant impact on quantity of knowledge workers' productivity but not on quality of knowledge workers' productivity. Additionally, knowledge-based performance appraisal was not found to have
\end{abstract}

its positive as well as significant impact on quality and quantity of knowledge worker's productivity.

Keywords-Knowledge-Based HRM Practices, KnowledgeBased Recruiting Practices, Knowledge-Based Training and Development Practices, Knowledge-Based Performance Appraisal Practices, Knowledge-Based Compensation Practices, Quality of Knowledge Workers' Productivity, Quantity of Knowledge Workers' Productivity.

\section{INTRODUCTION}

In this data driven and knowledge based era, the dependence of manual workers has since switched the focus onto the productivity of knowledge workers. With ideas of knowledge management (KM) emerged into the mainstream, it has brought knowledge work to the center of discussions on increase of productivity provided by knowledge workers. Some examples of knowledge workers are scientists, architects, lawyers, and lecturers. The influence of knowledge workers is often stated as strategical and also respected in the knowledge-based economy and urban area expansion. Rather than highly managed by superiors, knowledge workers tend to have more autonomy, and they have to manage themselves.

The research purpose of this paper is to examine HR practices which affect the quantity plus quality productivity of the knowledge workers in Malaysian universities. Knowledge workers such as lecturers, professors and staffs were studied under the scope of this research. While there are studies regarding $\mathrm{KM}$ practices on firms and companies, however, there are only few that focus on KM practices, to be specific, 
the knowledge-based HRM practices, in universities. Academic workers such as lecturers, admin staffs, research assistants, professors, and tutors are all knowledge workers in universities that are under researched. HRM practices play a vital role in retaining the quality staff. This is because recruiting the right knowledge worker for the right job could affect the productivity of the knowledge workers. Recruiting persons that are not suitable for teaching or working in a particular field may affect the quality and quantity of their productivity. Universities sometimes use inappropriate training and development practices for their employees, which then may affect the productivity of the knowledge workers. The appropriate performance appraisal practices could also affect the knowledge workers' productivity.

The core objective of this research is to understand the influence of each of the knowledge-based HRM practices on knowledge worker's productivity in universities so that the best set of HRM practices could be suggested to implement with the intention of increasing the quantity as well as the quality of knowledge workers' productivity in universities. The primary research question is "what is the impact of knowledge-based HRM practices namely knowledge-based recruiting practices, knowledge-based training and development practices, knowledge-based performance appraisal practices, and knowledge-based compensation practices on the quality and quantity of the knowledge worker's productivity?

\section{A. Development of Theoretical Framework}

This study has developed the theoretical framework by integrating Herzberg's Two-Factor Theory, Expectancy Theory, and MacGregor's Theory X and Theory Y. Alias Motivator-Hygiene theory, the Two-Factor theory is a motivation theory introduced by a psychologist named Frederick Irving Herzberg. The researcher summarizes as the work itself is the motivation [11]. Hygiene factors concern with the situation of the work, for example, compensation and working environments. 'Hygiene' implies environmental and preventative. These factors by themselves can affect neither content nor inspire the employees to be productive, rather, they are typically used as to stop job displeasure of employees, with only minimal impact on optimistic job attitudes. The twofactor theory by Herzberg persuasively stresses the positive significance in intrinsic motivating factors and emphases on the necessity concerning both monetary and non-monetary satisfactory factors when creating and implementing the various system of rewards [2].

On the other hand, the Expectancy theory demonstrates that great motivation is visible when people have ideas of what actions are needed for them for obtaining the reward, expects that they are possible to obtain the reward and expects that the particular reward that they receive is going to be worth. Initially comprised of past studies, this theory of expectancy was in the valence-instrumentality-expectancy (VIE) theory that was expressed by [27].

Whereas, in Theory X and Theory Y, introduced by [19] identifies two different motivation styles that can be applied by the management. They are widely used in HRM, organizational behaviour, communication, and development. [19] states in Theory $X$ that the typical employees are inherently not fond of working, and will try to do lesser work, or prone to escape from responsibility whenever they can. The employees are also seen as lazier and merely work for their interest, or for the- sustainable income. In this case, the managers will need to utilize the rewards or punishments as the motivation for the employees to work, because the employees are believed to be not motivated unless there is a reward or they are scared of the penalties. For theory X, [19] proposed the hard plus the soft method of HRM. The hard method translates into intense regulation and observation on employees, in addition to having a punishment system on employees. The soft approach has softer rules on the employees, and uses a reward system for the employees. However, [19] said that both of the approaches are too extreme, which he recommends managers locate the middle ground between the two approaches. Because of these expectations on the employees, this theory determines the usual workforce will operate much more efficiently underneath a hands-on approach by managers. Managers that apply Theory $\mathrm{X}$ consider all engagements as traceable to the individual's responsibility. In contrast, Theory $\mathrm{Y}$ sees employees as inherently motivated to work and enjoy their work, while try to improve themselves without thinking about a reward. Managers tend to have a brighter outlook on these employees, as they do not need tight supervision to produce work with excellent quality. They take high responsibility for their work and internally have high motivation to work [19]. Most knowledge workers would fall into this category, because most of their work needs intrinsic motivation, such as scientists or professors researching a particular field. They have a tendency to have a great quantity of self-motivation. Therefore, managers that utilize Theory $\mathrm{Y}$ tend to allow employees to have lesser limitations on their work. It encourages creativity and decentralization, which can help employees to achieve organization's goals.

By integrating the concepts of above three theories, the HRM practices namely knowledge-based recruiting practices, knowledge-based training and development practices, knowledge-based performance appraisal practices, and knowledge-based compensation practices have been taken as independent variables. On the other hand, Quality of knowledge worker's productivity which is measured by job autonomy, which substitutes the range of other critical qualitative dimensions of productivity such as innovation and customer satisfaction [7, 20] and quantity of knowledge worker's productivity which is measured by using timeliness and task efficiency of knowledge workers [7] are taken as the dependent variables in the theoretical framework as shown in Figure 1. 


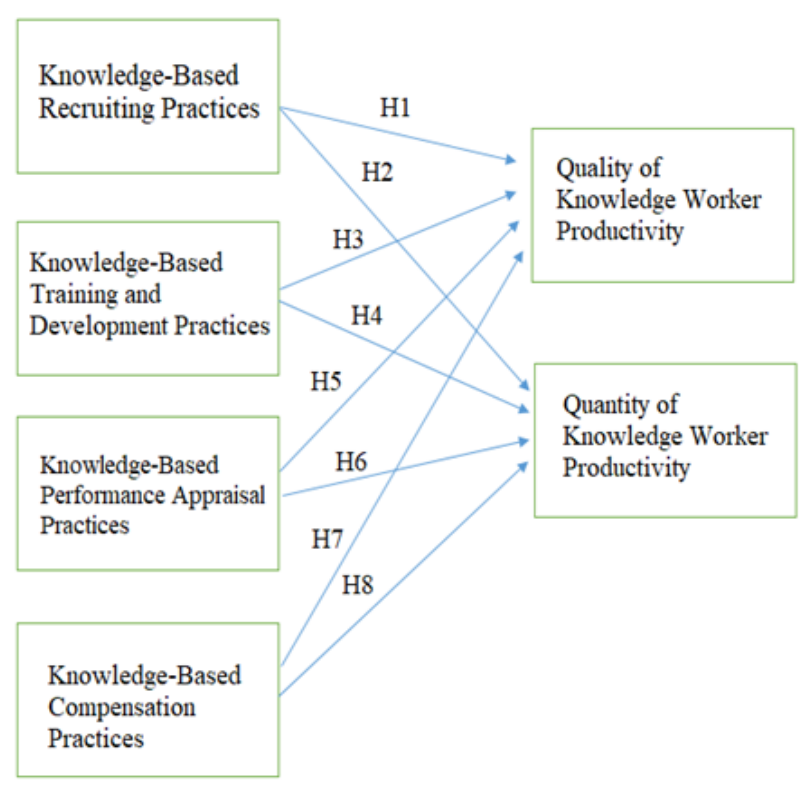

Fig.1: Proposed Theoretical Framework

\section{B. Development of Hypotheseas}

1) Influence of Knowledge-based Recruiting Practices on Knowledge Worker's Productivity

Several past studies have reported a connection between knowledge-based recruiting practices and the productivity of knowledge workers [4, 13, 17, 21, 24, 25]. In a nutshell, knowledge-based recruitment should involve robust and clear emphasis in selecting applicants with appropriate knowledge, learning and also networking competencies [14, 24]. Recruiting the correct candidate for the right job can affect their productivity on work. Hence, we can hypothesize the positive influence of knowledge-based recruiting practices on worker's productivity.

H1: There is a positive influence of knowledge-based recruiting practices on quality of knowledge worker's productivity.

$\mathrm{H} 2$ : There is a positive influence of knowledge-based recruiting practices on the quality of knowledge worker's productivity.

\section{2) Influence of Knowledge-Based Training and} Development Practices on Knowledge Worker's Productivity

By constructing and executing activities for training and also development, companies can adjust the fit between the current and necessary abilities and understanding of the staffs, thus contributing for the creating regarding knowledge [6,21]. Enhancing employees' creative thinking processes and task proficiency can also be done throughtraining $[6,12,15]$.
Training and development that are knowledge-based will comprise of frequently training the employees' proficiency and knowledge depth and breadth, personalizing exercises to learn certain essentials and also ensuring the employee development is continuous [14]. Some studies show that training and development practices and the knowledge worker's productivity have a relationship [3,12, $13,14,15,21,26]$. As training and development in a company may make or break a worker's productivity, we thereby assume that knowledge-based training and development practices have a relationship with knowledge workers' productivity. Hence the hypotheses are stated as follow:

H3: There is a positive influence of knowledge-based training and development practices on quality of knowledge worker's productivity.

H4: There is a positive influence of knowledge-based training and development practices on the quantity of knowledge worker's productivity.

3) Influence of Knowledge-Based Performance Appraisal Practices on Knowledge Worker's Productivity

Performance evaluation is an appropriate mechanism for managing the employee's behaviours $[13,14]$. Managers ought to deliberately and explicitly include the criteria of performances that have relationships to the process of knowledge in order to enhance them [14]. Performance appraisal ought to emphasise on the development and feedback to the employees [6,16]. Furthermore, receiving feedback aids the employees to recognize the weakness or problems amongst their performance and goals [23]. Thus, motivating staffs to put more effort into their work [12]. There are a few studies that show direct and indirect association between knowledge-based performance appraisal practices and knowledge worker productivity $[12,13,14,16,17,21,23,25]$. We can see that performance appraisal may be a crucial part in maintaining the productivity of workers, as having a good target and performance may better motivate the employees. Other than that, [19] Theory X and $\mathrm{Y}$ assume that performance evaluation and supervision is essential in motivating workers, which affects their productivity. We will assume that there is a positive impact of knowledge-based performance appraisal practices on the quality and quantity of knowledge worker's productivity. Thus, following hypotheses have been developed.

H5: There is a positive influence of knowledge-based performance appraisal practices on quality of knowledge worker's productivity.

H6: There is a positive influence of knowledge-based performance appraisal practices on the quantity of knowledge worker's productivity.

4) Influence of Knowledge-based Compensation Practices on Knowledge Worker's Productivity 
The policies of compensation and remuneration can encourage the treatment of knowledge in companies. Managers may perhaps utilise tangible and intangible enticements to motivate workers to share, produce and apply their knowledge for the company [1, 5, 12, 13, 22]. Studies have stated that this system of incentive is a necessary mechanism for encouraging workers to share their knowledge among themselves and producing fresh ideas for their work [1]. To sum up, knowledge-based compensation suggests that fulfilling employees in regards to their assistance and offerings to the company is the essential procedures of distributing, creating and applying of their knowledge [14]. Between knowledge-based compensation practices and productivity of knowledge worker, studies in [13], [14], [21], [12], and [25] indicates that indeed there is connection amongst the two variables. In addition, Two-Factor Theory by [10], Theory X by [19] and Expectancy Theory by [27] assume that compensations are crucial in maintaining the workers' productivity. Thereby, we have hypostasized a positive connection between knowledge-based compensation practices and the quality and quantity of workers' productivity as follow:

H7: There is a positive influence of knowledge-based compensation practices on quality of knowledge worker's productivity.

H8: There is a positive influence of knowledge-based compensation practices on the quantity of knowledge worker's productivity.

\section{Methodology}

\section{1) Survey Design, Data Collection Method, and Sampling}

This study used a standard survey instrument among universities' staff members including lecturers, admin staffs, research assistants, professors, and tutors from Malaysian private universities located at Selangor and Kuala Lumpur. Total 129 respondents completed the questionnaire. This study is a correlational study in a cross-sectional setting and respondents were accessed using non-probability sampling techniques. All the constructs of survey instrument were adopted from existing studies that were again adapted during pretesting for final survey. 7 items of knowledge-based recruiting practices, 5 items of knowledge-based training and development practices, 7 items of knowledge-based performance appraisal practices, and 6 items of knowledgebased compensation practices were adapted from $(14,18,25]$.
Quality of knowledge worker's productivity and quantity of knowledge worker's productivity measured with 3 items were adapted from [20]. Moreover, G* Power analysis was conducted to calculate the minimum sample size. In order to analyse the current framework, which consists of 4 predictors, a sample size of at least 85 was needed for a 0.80 power to be created for this particular research model. However, the researcher tried to achieve data from 129 respondents, as it would create a power of 0.95 for the research model.

\section{DATA ANALYSIS AND RESULTS}

These demographic profiles of the respondents were analysed using SPSS. The majority of the respondent were between 21 to 30 years old $(45 \%)$ and 31 to 40 years old $(34.1 \%)$, and more than half of the respondents were female $(62.8 \%)$. This shows that there were more young workforces in this knowledge industry. The majority of the respondents were Malay (41.9\%) subsequently by Indian (28.7\%) and Chinese (24\%). The highest education of the respondents was mostly Bachelor's Degrees (41.1\%) and $\mathrm{PhD}$ (31.8\%), with Master Degree (16.3\%) and Diploma (10.9\%) following up. The work experience of the respondents was majorly in 1-3 years $(41.9 \%)$ and $7-9$ years $(31 \%)$, following up by 10 and above $(21.7 \%)$ and lastly $4-6$ years $(5.4 \%)$. The majority of respondents' universities' locations were located in Selangor $(48.1 \%)$ and Kuala Lumpur (38.8\%) as due to non-probability sampling and time constraints, the research is mostly done in these two locations. The positions of the respondents were admin staffs $(43.4 \%)$ and senior lecturers (34.9\%), following by professors $(10.9 \%)$, associate professors $(6.2 \%)$ and research assistants $(4.7 \%)$. Lastly, half of the years of working by the respondents in their universities were 2 years and less $(54.3 \%)$, following by $6-10$ years $(31.8 \%)$ and $3-5$ years $(11.6 \%)$, with minimal in $11-20$ years $(0.8 \%)$ and 21 years or more $(1.6 \%)$.

\section{A. Inferential Data Analysis}

For inferential data analysis, PLS-SEM technique was used. Based on recommendations of [8], measurement model analysis was conducted prior analysing structural model. The measurement model assessment contains the assessment of the relations among the indicators and their equivalent constructs. All the constructs were found to have acceptable reliabilities including Cronbach's Alpha, Composite Reliability, as well as sufficient Average Variance Extracted as shown in Table 1. 


\begin{tabular}{|c|c|c|c|c|}
\hline Constructs & $\begin{array}{c}\text { Cronbach's } \\
\text { Alpha }\end{array}$ & Rho_A & $\begin{array}{c}\text { Composite } \\
\text { Reliability }\end{array}$ & $\begin{array}{c}\text { Average } \\
\text { Variance } \\
\text { Extracted } \\
\text { (AVE) }\end{array}$ \\
\hline KBCP & 0.83 & 0.839 & 0.875 & 0.540 \\
\hline KBPA & 0.835 & 0.841 & 0.876 & 0.503 \\
\hline KBRP & 0.835 & 0.851 & 0.875 & 0.502 \\
\hline KBTD & 0.700 & 0.707 & 0.816 & 0.526 \\
& & & & \\
\hline QKWP & 0.774 & 0.794 & 0.868 & 0.688 \\
& & & & \\
\hline QUKWP & 0.778 & 0.791 & 0.870 & 0.691 \\
& & & & \\
\hline
\end{tabular}

TABLE 1

SCORES OF RELIABILITIES AND CONVERGENT VALIDITY (EVALUATION OF MEASUREMENT MODEL)

Moreover, the Heterotrait-Monotrail Ratio (HTMT) proposed by [9] was also assessed to determine the discriminant validity. All the items' value was found below 0.90 , which satisfy the conditions of HTMT as shown in Table 2.

\begin{tabular}{|c|c|c|c|c|c|c|}
\hline & KBCP & KBPA & KBRP & KBTD & QKWP & QUKWP \\
\hline KBCP & & & & & & \\
& & & & & & \\
\hline KBPA & 0.893 & & & & & \\
& $(0.759$, & & & & & \\
& 0.978 & & & & & \\
\hline KBRP & 0.767 & 0.717 & & & & \\
& $(0.622$, & $(0.551$, & & & & \\
& $0.866)$ & $0.828)$ & & & & \\
\hline KBTD & 0.821 & 0.830 & 0.752 & & & \\
& $(0.658$, & $(0.685$, & $(0.685$, & & & \\
& $0.964)$ & $0.964)$ & $0946)$ & & & \\
\hline QKWP & 0.65 & 0.601 & 0.591 & 0.594 & & \\
& $(0.423$, & $(0.342$, & $(0.381$, & $(0.352$, & & \\
& $0.784)$ & $0.776)$ & $0.753)$ & $0.751)$ & & \\
\hline QUKWP & 0.662 & 0.594 & 0.666 & 0.692 & 0.894 & \\
& $(0.436$, & $(0.376$, & $(0.452$, & $(0.428$, & $(0.872$, & \\
& $0.830)$ & $0.793)$ & $0.812)$ & $0.830)$ & $0.812)$ & \\
& & & & & & \\
\end{tabular}

TABLE 2

HETEROTRAIT-MONOTRAIT RATIO (HTMT)

After analysing the measurement model, structural model was also assessed based on suggestions of [8]. All items' VIF values were assessed that were found below 5 indicating no multicollinearity issues.

The PLS model of bootstrapping's outputs, which demonstrates the standardized path estimates are shown in Table 3 as below:

TABLE 3

TESTING OF HYPOTHESES

\begin{tabular}{|c|c|c|c|c|c|c|}
\hline & $\begin{array}{c}\text { Original } \\
\text { Sample } \\
(\mathbf{O})\end{array}$ & $\begin{array}{c}\text { Sample } \\
\text { Mean } \\
(\mathbf{M})\end{array}$ & $\begin{array}{c}\text { Standard } \\
\text { Deviation } \\
(\mathbf{S T D E V})\end{array}$ & $\begin{array}{c}\text { T Statistics } \\
(|\mathbf{O} / \mathbf{S T D E V}|)\end{array}$ & $\begin{array}{c}\mathbf{P} \\
\text { Values }\end{array}$ & Decision \\
\hline $\begin{array}{c}\text { KBRP -> } \\
\text { QKWP }\end{array}$ & 0.216 & 0.224 & 0.110 & $* \mathbf{1 . 9 5 9}$ & 0.051 & Supported \\
\hline $\begin{array}{c}\text { KBRP -> } \\
\text { QUKWP }\end{array}$ & 0.296 & 0.304 & 0.099 & $* * * \mathbf{3 . 0 0 3}$ & 0.003 & Supported \\
\hline $\begin{array}{c}\text { KBTD -> } \\
\text { QKWP }\end{array}$ & 0.077 & 0.073 & 0.092 & 0.834 & 0.404 & $\begin{array}{c}\text { Not } \\
\text { Supported }\end{array}$ \\
\hline $\begin{array}{c}\text { KBTD -> } \\
\text { QUKWP }\end{array}$ & 0.188 & 0.182 & 0.098 & $* \mathbf{1 . 9 1 1}$ & 0.057 & Supported \\
\hline $\begin{array}{c}\text { KBPA -> } \\
\text { QKWP }\end{array}$ & 0.130 & 0.127 & 0.141 & 0.919 & 0.359 & $\begin{array}{c}\text { Not } \\
\text { Supported }\end{array}$ \\
\hline $\begin{array}{c}\text { KBPA -> } \\
\text { QUKWP }\end{array}$ & 0.042 & 0.040 & 0.135 & 0.311 & 0.756 & $\begin{array}{c}\text { Not } \\
\text { Supported }\end{array}$ \\
\hline $\begin{array}{c}\text { KBCP -> } \\
\text { QKWP }\end{array}$ & 0.249 & 0.246 & 0.101 & $* * \mathbf{2 . 4 6 8}$ & 0.014 & Supported \\
\hline $\begin{array}{c}\text { KBCP -> } \\
\text { QUKWP }\end{array}$ & 0.206 & 0.217 & 0.103 & $* * \mathbf{1 . 9 9 5}$ & 0.047 & Supported \\
\hline
\end{tabular}

${ }^{a}$ Notes: Critical t values $* 1.65$ (significance level $=10 \%$ ), $* * 1.96$ (significance level $=5 \%$ ) and $* * * 2.57$ (significance level $=1 \%$ ).

Table 3 shows the direct impact of KBRP on QKWP. The result shows that $\mathrm{H} 1$ is supported because $\mathrm{t}$-value is significant $(\beta=0.216, \mathrm{t}=1.959)$. This means the positive impact of KBRP on QKWP is significant. It also shows the direct impact of KBRP on QUKWP. The result clearly shows that H2 is supported because $t$-value is significant $(\beta=0.296, t=3.003)$. This means there is a positive impact of KBRP on QUKWP which is also significant. Moreover, result reveals that $\mathrm{H} 3$ is not supported because $\mathrm{t}$-value is non-significant $(\beta=0.077, \mathrm{t}=$ 0.834 ). This means the positive impact of KBTD on QKWP is not significant. The result indicates clearly that $\mathrm{H} 4$ is supported because $t$-value is significant $(\beta=0.188, t=1.911)$. This means the positive impact of KBTD on QUKWP is significant. However, the result shows that H5 is not supported because $\mathrm{t}$-value is non-significant $(\beta=0.130, \mathrm{t}=0.919)$. This means the positive impact of KBPA on QKWP is not significant. Likewise, the result shows that H6 is not supported because $\mathrm{t}$-value is non-significant $(\beta=0.042, \mathrm{t}=0.311)$. This means the positive impact of KBPA on QUKWP is not significant. The result reveals that $\mathrm{H} 7$ is supported because $\mathrm{t}$ value is significant $(\beta=0.249, \mathrm{t}=2.468)$. This means the positive impact of KBCP on QKWP is significant. The result indicates that $\mathrm{H} 8$ is supported because $\mathrm{t}$-value is significant $(\beta$ $=0.206, \mathrm{t}=1.995)$. This means the positive impact of $\mathrm{KBCP}$ on QUKWP is significant. 
R-Square (Coefficient of Determination) which measures the variance proportion in a latent endogenous variable, was also assessed. R2 values of QKWP and QUKWP were found 0.341 and 0.399 respectively that indicate the high predictive accuracy of the model according to Cohen (1988). Moreover, f2 effect sizes were also assessed. Findings show that KBRP has small effect on both QKWP (0.036) and QUKWP (0.074), KBTD have no effect on both QKWP (0.005) and QUKWP (0.030), KBPA have no effect on both QKWP (0.010) and QUKWP (0.001), KBCP has small effect on both QKWP (0.035) and QUKWP (0.026).

The Q2 values were also analysed to determine the predictive relevance for the specific reflective endogenous constructs. Q2 values of QKWP and QUKWP were 0.208 and 0.243 respectively which indicate medium relevance for the endogenous constructs.

\section{B. Discussion and Conclusion}

The findings show that knowledge-based recruiting practices would enhance the quality of knowledge worker's productivity. The result is consistent with [14, 21, 4, 24]. One possible reason of acceptance of this finding is that in the context of universities, recruiting practices can impact the quality of knowledge worker because they are usually selected and hired based on their expertise and knowledge in the industry. Therefore, they may be motivated to produce quality works after they are employed by the university. As a result, knowledge-based recruiting practices have a positive impact on the quality of knowledge worker's productivity. The results also show that knowledge-based recruiting practices would improve the quantity of knowledge worker's productivity. This result is consistent with [14], [21], and [4] One possible reason for this finding is that knowledge workers may be motivated to produce more work as the university had employed them because they think that these workers presents the best fit for the organization. In order for them to be selected and promoted, the workers would work harder to deliver good outcome. As a result, knowledge-based recruiting practices have positive influence on the quantity of knowledge worker's productivity. $\mathrm{H} 3$ is not supported because the results show that knowledge-based training and development practices would not improve the quality of knowledge worker's productivity. This result is consistent with other studies [26, 25, 12]. Though, it is not consistent with [14], [21], [3] and [15], who found that knowledge-based training and development practices would enhance the quality of productivity. The potential explanation for this finding is that training and development practices conducted by the universities may have not focused much on the quality of the knowledge workers' work. Therefore, the workers may negate the importance of their quality they deliver. On the other hand, the findings also show that knowledge-based training and development practices would improve the quantity of knowledge worker's productivity. This result is consistent with [13], [14], and [21]. Though, it is not consistent with [25] and [12], who found that knowledge-based training and development practices would not improve the quantity of productivity. A possible explanation could be that rather than emphasizing the trainings and development practices on the knowledge workers' quality, universities may have designed them more to enhance the quantity of the work produced by them, hence, this could motivate employees to work based on how much they can produce, instead of enhancing the quality of their work.

H5 is not supported because the finding shows that knowledge-based performance appraisal practices would not improve the quality of knowledge worker's productivity. This result is consistent with [25] and [12]. Though, it is not consistent with other studies $[13,14,21]$ that found that knowledge-based performance appraisal practices would improve the quality of productivity. The potential explanation for this finding would be that performance appraisal may undermine their quality of productivity because rather than giving them autonomy in working, performance appraisal determines how well workers are doing based on their KPI. Therefore, it may affect their motivation to produce good quality work. H6 is also not supported because the finding shows that knowledge-based performance appraisal practices would not improve the quantity of knowledge worker's productivity. The outcome is consistent with [25] and [12]. Though, it is not consistent with [13], [14], [21], and [23] who found that knowledge-based performance appraisal practices would improve the quantity of productivity. The possible reason of this finding is that the appraisal tools used by the universities may not have influence on the knowledge workers as they may not care too much about the appraisals compared to other HRM practices, therefore, the quantity of the productivity of knowledge workers is affected. On the other hand, $\mathrm{H7}$ is supported as the finding shows that knowledgebased compensation practices would improve the quality of knowledge worker's productivity. This outcome is consistent with [13], [14], [21], and [25]. One of the possible reasons of this finding is that knowledge workers view compensation as a way to motivate themselves, and the compensation requires high quality works. Therefore, they are more likely to be encouraged by the rewards they receive to be more productive and quality work. Likewise, $\mathrm{H} 8$ is also supported as the finding shows that knowledge-based compensation practices would improve the quantity of knowledge worker's productivity. This result is consistent with [13], [14], [21], [23], and [25]. Possible clarification for this result can be employees assess the exchange relationship with the university concerning the compensation they obtain. When workers recognise that the universities value them by sharing profits, they give in return to the universities by making more efforts on their careers [12].

\section{LIMITATIONS AND FUTURE RECOMMENDATIONS}

Regardless of numerous implications of the research, there are also a few limitations that are desired to be reflected while understanding the results from the research itself. Firstly, this 
research has only examined a few universities in selected states. Thus, it is possible that different universities in different states could misperceive the outcome. The findings of this research may not be generalised on all the universities in the country. Secondly, the data obtained in the research was constructed on the cross-sectional research design wherein data was obtained at single point of time. Hence, subject matters' patterns and trends cannot be determined over an extended period. Thirdly, this research was conducted in the Malaysian universities' context only, the results cannot be applied to other countries, as structural and administrative practices may differ from one culture to another. Consequently, the difference in culture and principles may cause variations in the clarification of this research's outcome. The results of this paper may not be generalised on other countries' universities. Fourthly, attributable to the nonprobability sampling methods that are used in this study, the results of this study cannot be generalised over the entire Malaysian universities' population.

To overcome the above limitations, the future studies should conduct research on other Malaysian universities located on all other Malaysian states. Secondly, future researchers can design a longitudinal design to assess the impact of these HRM practices over extended period. Thirdly, similar type of study could be conducted in other developing countries that may reveal different results. Lastly, future studies can use random sampling technique to generalize the findings of their studies over all Malaysian universities.

\section{REFERENCES}

[1] Andreeva, T., and Kianto, A., "Knowledge processes, knowledge-intensity and innovation: a moderated mediation analysis", Journal of Knowledge Management, vol.15, no.6, pp.1016-1034, 2011.

[2] Armstrong, M., and Taylor, S. Armstrong's handbook of human resource management practice: Kogan Page Publishers, 2014.

[3] Butt, M. A., Nawaz, F., Hussain, S., Sousa, M. J., Wang, M., Sumbal, M S., and Shujahat, M., "Individual knowledge management engagement, knowledge-worker productivity, and innovation performance in knowledge-based organizations: the implications for knowledge processes and knowledge-based systems", Computational and Mathematical Organization Theory, pp.1-21, 2018.

[4] Currie, G., and Kerrin, M., "Human resource management and knowledge management: enhancing knowledge sharing in a pharmaceutical company", The International Journal of Human Resource Management, vol.14, no.6, pp.1027-1045, 2003.

[5] Dalkir, K. Knowledge management in theory and practice: Routledge, 2013 .

[6] Donate, M. J., and de Pablo, J. D. S., "The role of knowledge-oriented leadership in knowledge management practices and innovation", Journal of Business Research, vol.68, no.2, pp.360-370, 2015.

[7] Fernandez, R. The factors determining knowledge worker productivity within the Irish IT Industry. Dublin Business School, 2013.

[8] Hair, J. F., Hult, G. T. M., Ringle, C. M. and Sarstedt, M., "A Primer on Partial Least Squares Structural Equation Modeling (PLS-SEM)", 2nd ed, Thousand Oaks, CA: Sage, 2017.

[9] Henseler, J., Ringle, C. M., and Sarstedt, M., "A new criterion for assessing discriminant validity in variance-based structural equation modeling", Journal of the academy of marketing science, vol.43, no.1, pp.115-135, 2015 .

[10] Herzberg, F., Mausner, B., and Snyderman, B. B. The motivation to work ,Vol. 1: Transactionpublishers, 2011

[11] Herzberg, F. I. Work and the nature of man. Cleveland: World, 1996.

[12] Jiang, J., Wang, S., and Zhao, S., "Does HRM facilitate employee creativity and organizational innovation? A study of Chinese firms", The International Journal of Human Resource Management, vol.23, no.19, pp.4025-4047, 2012.

[13] Kianto, A., Shujahat, M., Hussain, S., Nawaz, F., and Ali, M., "The impact of knowledge management on knowledge worker productivity", Baltic Journal of Management, 2018.

[14] Kianto, A., Sáenz, J., and Aramburu, N., "Knowledge-based human resource management practices, intellectual capital and innovation", Journal of Business Research, vol.81, pp.11-20, 2017.

[15] Lau, C. M., and Ngo, H. Y., "The HR system, organizational culture, and product innovation", International business review, vol.13, no.6, pp.685 $703,2004$.

[16] Lepak, D. P., and Snell, S. A., "The human resource architecture: Toward a theory of human capital allocation and development", Academy of management review, vol.24, no.1, pp.31-48, 1999.

[17] Lepak, D. P., and Snell, S. A., "Examining the human resource architecture: The relationships among human capital, employment, and human resource configurations", Journal of management, vol.28, no.4, pp.517-543, 2002.

[18] Lopez-Cabrales, A., Pérez-Luño, A., and Cabrera, R. V., "Knowledge as a mediator between HRM practices and innovative activity", Human Resource Management, vol.48, no.4, pp.485-503, 2009.

[19] MacGregor, D. The human side of enterprise, Vol. 21: New York, 1960.

[20] Palvalin, M., Vuolle, M., Jääskeläinen, A., Laihonen, H., and Lönnqvist, A., "SmartWoW-constructing a tool for knowledge work performance analysis", International Journal of Productivity and Performance Management, vol.64, no.4, pp.479-498, 2015

[21] Razzaq, S., Shujahat, M., Hussain, S., Nawaz, F., Wang, M., Ali, M., and Tehseen, S., "Knowledge management, organizational commitment and knowledge-worker performance: The neglected role of knowledge management in the public sector", Business Process Management Journal, 2018.

[22] Scarbrough, H., "Knowledge management, HRM and the innovation process", International journal of manpower, vol.24, no.5, pp.501-516, 2003.

[23] Shipton, H., West, M. A., Dawson, J., Birdi, K., and Patterson, M (2006). "HRM as a predictor of innovation" Human resource management journal, vol.16, no.1, pp.3-27, 2006.

[24] Shujahat, M., Sousa, M. J., Hussain, S., Nawaz, F., Wang, M., and Umer, M., "Translating the impact of knowledge management processes into knowledge-based innovation: The neglected and mediating role of knowledge-worker productivity", Journal of Business Research, 2017.

[25] Tapio, I. H., Aino, K., and Mika, V., "Knowledge management practices and innovation performance in Finland", Baltic Journal of Management, vol.10, no.4, pp.432-455, 2015, doi:doi:10.1108/BJM-10-2014-0178.

[26] Usoro, A., and Abiagam, B., "Culture effect on knowledge management adoption in Nigerian hospitality industry", VINE Journal of Information and Knowledge Management Systems, vol.48, no.3, pp.314-332, 2018.

[27] Vroom, V. H. Work and motivation, Vol. 54, New York: Wiley, 1964 